
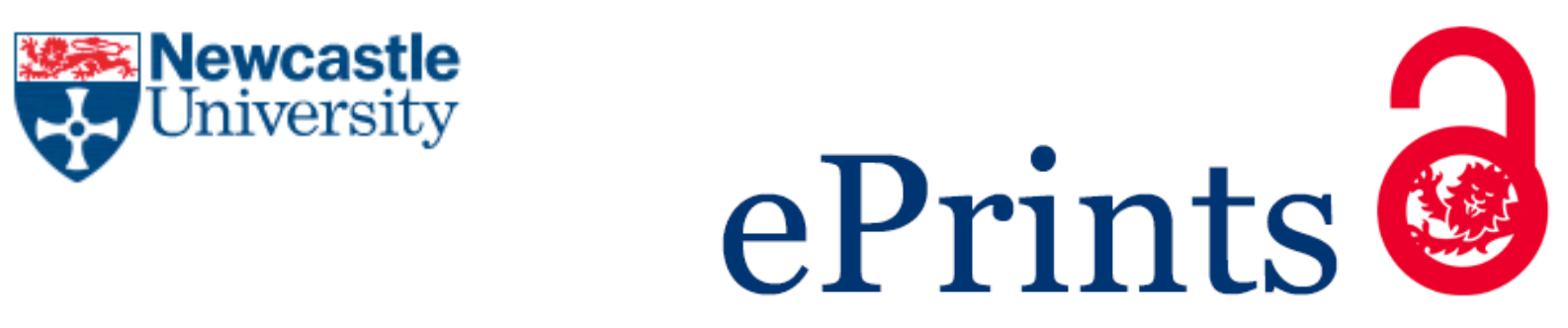

Leat D, Reid A, Lofthouse R. Teachers' experiences of engagement with and in educational research: what can be learned from teachers' views?. Oxford Review of Education 2015, 41(2), 270-286.

\title{
Copyright:
}

(C) 2015 Oxford Review of Education

The Version of Record of this manuscript has been published and is available in Oxford Review of Education, 16-03-2015

DOI link to article:

http://dx.doi.org/10.1080/03054985.2015.1021193

Date deposited:

$30 / 03 / 2015$

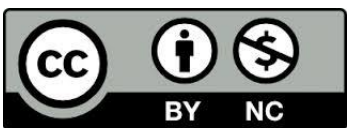

This work is licensed under a Creative Commons Attribution-NonCommercial 3.0 Unported License 
Teachers' experiences of engagement with and in educational research; what can be learned from teachers' views?

David Leat", Anna Reid and Rachel Lofthouse

The Research Centre for Learning and Teaching, Newcastle University, Newcastle upon Tyne, UK

*Corresponding author e-mail: David.Leat@newcastle.ac.uk 


\section{Teachers' experiences of engagement with and in educational research; what can be learned from teachers' views?}

In this paper, we explore what is known about teachers' engagement in and with educational research with a special emphasis on teachers' voice evoking their experience of participating in research. This will draw upon international contexts in order to suggest ways of utilizing the benefits of research in practice. Our review is framed around five key themes between which there are interesting links. The first theme is purpose and consequence, which highlights the dimensions of teachers' control and autonomy. This is related to the second theme teachers' learning and affective response. The third theme, agency, addresses the contextual factors influencing teachers' experience of research, which opens up the fourth theme concerning the degree of trust and collaboration that is experienced by teacher researchers. The final theme is contradiction. This phenomenon understood in the context of socio-cultural theory in that the teacher researcher is evolving practice and questioning the focus on aggregate examination results/targets and its associated technology. While the available evidence of teachers' experience of research is overwhelmingly positive, providing an acceleration of professional understanding and new perspectives, which reinvigorates those teachers who do engage, it is not always experienced as such. Overall, we underline the importance of dialogic approaches and ecological agency, which relate to teachers' multi-dimensional perceptions of and participation in research.

Keywords: teacher research; teacher inquiry; teacher voice, dialogical self; ; agency

\section{Introduction}

In this paper, we explore what is known about teachers' engagement in and with educational research with a special emphasis on teachers' voices. Educational research is a problematic concept (Stenhouse, 1981), drawing on multiple theoretical frameworks (Bryman, 2008), and subject to differing interpretations of whether practitioners should be involved and indeed to what end (Carr, 2007; Elliot, 2001). To complicate matters further, successful continuing professional development (CPD) can share many of the characteristics of teacher research. Thus many award bearing professional development courses, require participants to carry out a reflective project, which may replicate most, or all, of the characteristics of research. 
Furthermore in the twenty first century teachers' time is more closely mandated than ever before, thus any decision about engaging in or with research is increasingly one influenced by institutional and socio-political factors. Teachers' engagement in research needs to be seen in the context of their wider professional life, in which contractual duties are increasingly onerous.

It is also problematic to be definitive about teachers' relationship in and with research as there is a dearth of systematic surveys. We are dependent primarily on teachers' voices as represented in published research and generally such writing, usually authored by academics, quotes such voices as evidence in relation to other issues. Although we undertook systematic keyword searches, this proved an unrewarding strategy, as teachers' personal perspectives on research engagement are not readily accessible through such searches. We relied considerably on recommendations from key informants. We have a series of snapshots from different angles and of different individuals and groups in different circumstances and to bring order to this assemblage we have drawn upon particular interpretative frames, which we lay out later in this section. In this paper teachers' voices are always italicised, to help identify them.

Which teachers engage with and in research, where teachers get their research sources from, in what format and on what topics, are difficult questions to answer. A decade ago (Ratcliffe, 2004) the main sources reported were reading, in-service training, colleagues and publications of subject associations, with the internet rapidly becoming a primary location (Sanders, White, Sharp \& Taggart, 2005). The internet has almost certainly become pre-eminent as a source, but nonetheless mediation and guidance from university partners or school colleagues probably remains important. Given that it is generally a minority who will use research in any substantive manner, it is interesting to note that an Australian study (DETYA, 2000) suggests that the characteristics for those who access research include: they observe and question their own practice, have an eye for the bigger picture of educational change, have a moral purpose for their work and continually ask probing questions.

Our starting point for analysis is that we have an expectation that teachers who engage in and with research will incline towards a reflective disposition. We take a socio-cultural view of teachers' engagement in and with research. We equate engagement in and with research as a reification of agency, which in simple terms equates to the individual's capacity for action, in order to pursue meaningful personal goals in life. However, agency is increasingly being seen as a quality that resides in the context (Biesta \& Tedder, 2007). In the distinction between engaging with and engaging in research there is a sense that in implies a greater degree of 
immersion. Barnett and Coate's (2005) work on the outcomes of higher education suggests further elaboration of such distinctions may be productive. They refer to knowing, acting and being. They propose that 'knowing' refers to the core knowledge of a discipline; and that 'acting' foregrounds skills and actions that students (in our case these are the teachers) are expected to master and refers to how a student's expertise grows and develops through activity. The domain of 'being' denotes the formation of students' personality and identity. 'Knowing' readily equates to engaging with research, where research is seen as a body of knowledge to be accessed and to be acquired. Engagement in research can be discerned as at least two levels. The first would see teachers using research skills and therefore developing expertise in articulating good questions, conducting interviews, choosing appropriate psychometric measures, managing and analysing data and so on. The second level of engaging in research would see significant development in identity and the self, with repercussions for the teacher's personal agency. This is a socio-cultural interpretation of the implications of engaging in research, which implies an importance for the discourse and culture prevailing in many schools, which are influenced by policy imperatives. Accordingly, in subsequent sections we consider the following themes: purpose and consequence of teacher research, teachers' learning and affective response, agency, trust and collaboration, and finally contradiction and conflict generated by teacher research. We then turn to a discussion of teachers' experiences of research as an expression of the dialogical self (Hermans, 2001).

\section{Purpose and Consequence}

Writing in 2004, McLaughlin, Black-Hawkins and McIntyre (p.7) suggest that three purposes can be discerned in the teacher research tradition:

research and enquiry undertaken for primarily personal purposes; research and enquiry undertaken for primarily political purposes; and research and enquiry undertaken for primarily school improvement purposes. Often these are interwoven, not simple and distinguishable or as neat as here presented.

The first purpose is associated with the action research and reflective practitioner movements. The second tradition derives from concerns for democracy, equality and the transformation of society and is associated with the work of Freire (1970). The third tradition - school improvement - has evolved in conjunction with a political desire for evidence-based practice with a focus on student outcomes. Given increased emphasis on accountability, it seems likely that the last mentioned purpose has increased in importance. As a result the most prominent face of educational research involving teachers is the school effectiveness paradigm - related to the aphorism what works. This is reflected in the popularity of meta- 
analyses of evidence relating to the impact of interventions on student outcomes (Marzano, 2003; Hattie, 2009).

During the emergence of action research by teachers, stimulated by the work of Lawrence Stenhouse (1975) in the UK, there was greater latitude for teachers. Schools and teachers were not under such close scrutiny, epitomised in education in the term 'performativity' (Ball, 2003), which is in essence the managerial control of public services through numerical targets. Such accountability pressures and their constraints on teachers are equally well known in the United States (Craig, 2004). In England, prior to the late 1980s, there was greater freedom for teachers to determine their pedagogical practice and to formulate their own curriculum. This was curtailed initially, via the introduction of a National Curriculum, by detailed specification of taught content - termed input regulation. Increasingly this has been replaced by 'output regulation' manifested through examination result targets and high levels of external accountability (Nieveen \& Kuiper, 2012). So as regulation has been increased so the scope for curriculum imagination has been choked off. Rickinson (2005) summarised a number of studies of research use by practitioners and showed that most reasons given were practice related, such as improving practice in various ways, prompting reflection and validating proposals, with little suggestion of more political, curriculum oriented intentions. Jones and Stanley (2010, p.160) in reporting on a university-schools research partnership in England describe the way in which everyone involved became enmeshed in the imperatives of a performativity culture:

The practitioners in the three schools were embedded within a national agenda of raising standards through school improvement, and thus their mission was one of marketing the educational enterprise rather than critically evaluating it. We would be deluding ourselves if we succumbed to the temptation to consider ourselves outside the culture of performativity.

However research can provide the legitimisation and justification for a particular values position that may not be particularly endorsed by current trends in school politics. This teacher involved in a research focused Learning to Learn project (L2L) in England (Higgins, Wall, Baumfield, Hall, Leat \& Woolner, 2006, p.30) describes their conviction, based on personal experience that metacognition is important in learning, being validated by external evidence: 
I had always believed that to be true and I had always striven to teach that way and here was something that underpinned my hunch and it was a fabulous moment and meant that I felt justified.

Elliott (2012) has critiqued the evolution of teacher research in England, arguing that it has become detached from the curriculum development theory advanced by Stenhouse (1975), in which the 'teacher as researcher' is at the centre of curriculum development and nothing is taken for granted. From this theoretical perspective the focus of teachers' research should be on how to effect worthwhile curriculum change in their classrooms and schoos, through systematic inquiry. Elliott argues that teacher research has predominantly become a captive of outcomes based education, focused on finding ways of being more effective in delivering predetermined knowledge outcomes. For Stenhouse the nature of knowledge was a matter of speculative understanding, always open to question, which prises open serious ontological and epistemological issues.

The effectiveness imperative is borne out in this extract from a secondary science teacher, who was participating in action research focusing on data loggers in science and their impact on student outcomes (Furlong, Salisbury \& Coombs, 2003 p. 19):

I'd not done this kind of research before and I think I'd underestimated the power it had for helping me learn about teaching and being able to identify things that work.

It seems that teachers' engagement in and with research is experiencing a strong gravitational pull towards school effectiveness approaches, with a consequent loss of critical autonomy. Thus in the Netherlands, Leeman and Wardekker (2014) report substantial difficulty in provoking teachers to consider the goals of education through engaging in research. They conclude that teachers avoid challenging the status quo in their schools, citing evidence from a teacher, explaining the reluctance to engage:

Moreover research is only valued as long as it contributes to the efficient teaching of take-for-granted aims: 'Doubts about our teaching principles are not valued much in our school' (p.55)

Cain, Holmes, Larrett and Mattock (2007, p. 101) suggest that amongst trainee teachers striving to meet mandated standards through a research-based approach there is an ongoing tussle between doing what is required and doing what seems right:

As teachers we are expected to be role models to our students and must expect to be treated as we treat them. (Mattock) Analysing many types of data has allowed me to 
investigate what I need to do to fulfil the monitoring and assessment standards to a professional level. (Holmes) I believe a more democratic approach with increased equality of power and engagement between teacher and student would result in a more healthy learning environment.(Larrett)

We conclude that most teachers are motivated to engage in research by the prospect of improving their classroom practice, however the direction and distance that they are prepared to pursue this is strongly influenced by context.

\section{Teachers' Learning and Affective Response}

Although the purpose of teacher research is constrained, Rickinson (2005) suggests that research utilisation is a process characterised by being 'active, selective, values rich, rewarding and developing'. The selective nature is further described as idiosyncratic and individual, as teachers' particular preferences and values influence their interest and engagement with research as identified by this special needs teacher, and reported in Furlong, Salisbury and Coombs (2003, p. 13.):

I just feel it [reading] makes your more PROFESSIONAL because you've had to go and examine something instead of just thinking of lesson plans and little Freddie in the front row [...]

In the US Richert (1996), reported in McLaughlin, Black-Hawkins and McIntyre (2004, p.7), summarises the effects of engaging in research in the very well-funded, Bay Region IV Professional Development Consortium:

a) It resulted in a renewed feeling of pride and excitement about teaching and in a revitalised sense of oneself as a teacher.

b) It reminded teachers of their intellectual capability and the importance of that capability to their professional lives.

c) It allowed teachers to see that the work that they do in school matters.

d) It reconnected many of the teachers to their colleagues and to their initial commitments to teach.

e) It encouraged teachers to develop an expanded sense of what teachers can and ought to do.

f) It restored in teachers a sense of professionalism and power in the sense of having a voice. 
This list demonstrates affective outcomes of engaging in research, in that teachers' values, working practices and agency can be altered. However it also suggests that there were some restrictive and negative aspects to their working environment that the teachers were encountering, and for which research engagement offered an antidote. This is also illustrated in the words of a student teacher engaged in a research project during their training in England, who draws attention to an unthinking routine style of work (Medwell \& Wray, 2014, p.72):

I have really contributed to new knowledge. It's made think about that. How you do that all the time, I suppose, but having this as outside my teaching lessons it has made me think a lot more than I do when I am on planning and evaluating treadmill.

Different modes of cognition and reflection are drawn out in Eraut's (2007) distinction between instant/reflex, rapid intuitive and deliberative/analytical as modes of cognition. As Eraut makes clear, as practitioners tackle classroom problems, it is most explicit mode of cognition, which theoretically encourages both engagement with and in research:

The deliberative/analytic column is characterised by explicit thinking by individuals or groups, possibly accompanied by consultation with others. It often involves the conscious use of different types of prior knowledge, and their application to new situations (p. 407).

It is the conscious deliberate reflective processes that are most likely to be recorded as evidence of teachers' relationship with research. Experimentation and reflection, which form a part of most cyclical models of action research, have the capacity to help teachers develop an alternative, more distanced and critical view on their work and context. This is exemplified in the words of a teacher researcher in Newman and Mowbray (2012, p.462):

In terms of using the information gained through the Jean Denton project ... it (research) has enhanced and provided another layer (of understanding) about what we do ... it has given a deeper level perspective.

As teachers spend so much of their early careers trying to simplify classrooms and make them more predictable and manageable, it is understandable if significant professional learning is underpinned by undoing some of that routine and introducing new dynamics even where that comes at a certain emotional cost. Such interruptions generally involve teachers in a research like process in which evidence of student learning (or lack of learning) is examined and there 
may be significant challenges to existing beliefs about learning (Timperley, Wilson, Barrar \& Fung, 2007).

As was indicated earlier much teacher engagement in research is in the context of action research, where reflection is accompanied by an action component and it is the action and its perceived impact on students that is so compelling to many (Medwell \& Wray, 2014, p. 74):

For four of my children, doing this research, has definitely improved their writing automaticity and may help their composing. It is big. .... I feel the impact of that theory in university for my children which I would never have thought about.

Finally it should be recognized that teachers learn about research through engaging in research. This is particularly the case where projects are sustained and there is an iterative dimension to learning, as suggested by this primary school research Learning to Learn (L2L) project coordinator (Higgins, Wall, Baumfield, Hall, Leat, Moseley \& Woolner, 2007, p 57):

Over three years we became more concerned to ensure that research design and methodology was more robust.

\section{Agency}

As indicated earlier agency refers to the individual's capacity for action, to have control over one's life and follow the bearings set by values and ambitions, but recent critiques of the concept have drawn attention to the importance of power relations in both constraining and legitimising agency (Eteläpelto, Vähäsantanen, Hökkä \& Paloniemi, 2013). Furthermore Biesta and Tedder (2007), emphasise the interplay of the individual and the social and argue that agency does not lie predominantly in the individual but in the context, so that agency is something that the individual achieves rather than something they possess. This is illustrated by a teacher researcher:

Leading a session taught me that I can grow as a learner and help others to understand sometimes abstract ideas. Because I am surrounded by children every day it sometimes seems that our own academic qualities are lost, so the course has enabled me to re-use them and improve them. (Kershner, Pedder \& Doddington, 2013, p. 41) 
Biesta and Tedder (ibid.) propose that agency is achieved as individuals engage in 'contextsfor-action', realising particular configurations of routine, purpose and judgement. They quote Emirbayer and Mische (1998, p. 963) who suggest that agency can be understood as:

Temporarily embedded process of social engagement, informed by the past (in its habitual aspect), oriented towards the future (as a capacity to imagine alternative possibilities) and 'acted out' in the present (as a capacity to contextualise past habits and future projects with the contingencies of the moment).

Biesta and Tedder go on to propose the term 'ecological agency' to represent the understanding that 'contexts-for-action' shape individual agency. This perspective on agency is pivotal in understanding teachers engaging in research as it is probable that teachers need favourable, ecological, conditions in which to engage in research. Such contextual factors are neatly summarised by McLaughlin, Black-Hawkins and McIntyre (2004. p.5), which include:

- External and internal agents support it (research). External agents, often colleagues in universities, are important in providing research knowledge and training. Internal support from heads, senior management and teacher colleagues is also significant.

- Access to libraries and other information resources in an accessible form was also important to teachers.

- There is the support of a group. This can be internal or external group but it is characterised by support, development and problem solving ....

Agency involves teachers' personal capacity to act in relation to the contingencies of their environments. As a result, they may exercise more or less agency at various times and in different settings because neither their personal experiences nor their individual contexts remain fixed. However even where conditions may appear to be superficially conducive to research engagement, it is possible that agency may not develop as expected, perhaps because there is a lack of skill in leading meetings so that helpful conversational routines are absent (Horn \& Little, 2010). In performative school cultures it may be that supportive conditions for research wax and wane (Higgins et al., 2006, p.26):

I think it goes in waves really, if that makes sense? When we start something new, when we put out the learner logs this year, everyone was talking about 
them, and we sort...then we...is there a problem or is it a specific child, then this will come up again and we'll talk about it again.

Sustaining involvement in research over a period of years brings greater chance of developing a more critical stance, proceeding from a procedural autonomy to a critical autonomy (Ecclestone, 2000). In certain circumstances the context may provide conditions in which school students become involved as researchers which has a feedback effect on the inquiry system, as illustrated from the L2L project (Wall et al., 201099, p.61):

During the data-gathering phase of Stage One regular meetings were held with the researchers, to help keep enthusiasm buoyant, to answer queries and to give the researchers the chance to swap experiences and stories.... . The learning logs were collected and the results laboriously collated. During this process it became clear that the information gathered was very rich in terms of student comment and that Stage Two would have to start with 1:1 interviews with the researchers to explore their feelings and conclusions more thoroughly.

\section{Trust and Collaboration}

Networks are a recurring phenomenon of teacher research and epitomise teacher collaboration in research. The concept of communities of practice (Wenger, 1998) has been influential in this regard and several attempts have been made to create such communities (Palincsar, Magnusson, Marano, Ford \& Brown, 1998). Indeed, in England very considerable investment was made into Networked Learning Communities. A key question is whether the networks are engineered as a top down, imposed innovation or represent, to any extent, a self-organised natural expression of collective intent. This is reflected in the wide variety of purposes surveyed by Lieberman and Grolnick (1996) in 16 US school networks which ranged from support for a particular teaching of writing programme to people who shared values about progressive education.

Whilst support from leaders and the environment is critical, the intricacies of collaboration are inestimable and constitute an important dimension of agency. It is hard to act alone, against prevailing norms and discourse (Newman \& Mowbray, 2012, p.460):

When we started ... I wouldn't have had any of those skills without the Jean Denton Group ... It's very difficult to connect with other people in a similar level of training 
... being part of a group gave me the opportunity to engage with people who were interested at that level and enhance the expertise at that level.

Notwithstanding the importance of general factors in creating a supportive climate, it is hard to ignore the relevance of key individuals who are able to encourage and enthuse other members of staff in their institutions. Rathgen (2006, p. 584), for example, recounts the confidence that Graham Nuttall in New Zealand gave teachers in his projects through suggesting that it was a privilege to be in their classrooms and she quotes one of them as follows:

So that the issue of having to trust the people themselves was a critical part ... The research team worked very hard to assist me to be part of the research project.

Newman and Mowbray (2012, p. 464) found comparable admiration amongst teachers for their university lead partner:

I think the support of the leader of the group ... her expertise, research skills as a practitioner and as an academic was absolutely invaluable. Having it facilitated by an academic was particularly invaluable given her experience in the field and her academic knowledge.

The subtle practices required of, and offer made by, external partners were recognised by two teachers who were part of a Creative Action Research Award Scheme, firstly speaking of the research mentors, and secondly of school-linked creative practitioners:

Our research mentor was absolutely excellent. [...] they were able to be helpful and directive without assuming control. Everything was a suggestion, all valuable, and this helped us to focus our enquiry [...]. They were really supportive and informative and did genuine mentor stuff, that is, working alongside us. (Comerford Boyes, Reid, Fox \& Brain, 2005, p.35)

the action research aspect has been the whole thing, we have used our creative practitioner as a fieldworker who has a creative background, one with insight and tacit knowledge. (Comerford Boyes, Reid, Fox \& Brain, 2005, p.34) 
Three stages of development in teacher research engagement were identified in the work of one school in a funded School Based Research Consortium (Leat, Lofthouse \& Taverner, 2006, p.668-9) and can be summarised as follows;

Stage 1: The personal. Teachers focused on their own understanding rooted in developing classroom practice and analysing data which emerged.

Stage 2: The collegial. The group setting (typically at a school level) became significant as a community in which research was designed, conducted and analysed, in an environment characterised by professional intimacy

Stage 3: The collective. The collegial group had developed sufficient confidence to work with others across the consortium (schools, local authority and university), in a wider range of settings.

However, these stages are not inevitable, as the collective and collegial stages can be inhibited. Lack of trust and collaboration can be debilitating as experienced by a teacher quoted by Castle (2006, p.1100) in the US:

I'm feeling torn between what I know and the lack of support from others. I am reflecting on the criticism of other teachers and some of the parents. Although there are critics of multi-age teaching, I have studied it and I know it will work.

Furthermore, the importance of the presence of trust is made apparent when it suddenly disappears, as if a balloon has deflated. In one L2L school a change of head teacher had a rapid and direct effect which was magnified by the indirect effect on other staff. Collaboration can be a delicate organism, very easily destroyed (Higgins et al., 2007, p.62): ... we are not as enthusiastic as we were... The things that haven't helped are when you are discouraged from the point of view that you feel not valued, that your work isn't valued... The other thing that hasn't helped is that we are not allowed to disseminate as such to other people. We did have one opportunity to give one session feedback but the Head looked disinterested and the rest of the staff felt that it wasn't particularly important.

\section{Contradiction and conflict}

The fifth and final theme is contradiction and conflict. We use the term contradiction as used in socio-cultural theory to denote the fact that research can often provide tools which set in train processes which begin to challenge or contradict the object (Engeström, 1987) of school activity. Sannino (2008), in the context of schools, terms such focus the dominant activity. One of the potential consequences of research which provokes contradictions is that teachers 
may choose to leave the classroom as they find it increasingly difficult to live with those contradictions.

Thus, engaging in research invites complication. It is common for teachers engaging in research to experiment and if their emerging research agendas and outcomes are unconnected to school improvement priorities there may be a schism between teacher researchers and school leaders or their peers. Castle (2006, p.1098) provides an example of first grade teacher whose research leads her to question orthodoxies:

I began to ask questions about those situations that seemed wrong to me. One year it didn't seem right that the goal was for the kids to get through the reading book rather than for them to make gains in reading. So I started questioning the way reading was taught. I wondered:

Why do I have to use three reading basals required by the state? I began to investigate other ways to teach reading that were better for children.

Equally senior leaders can overestimate the capacity of classroom teachers for research. Ebbutt (2000) reporting on the SUPER schools judged that only two of six had an established research culture and even in those two there were trenchant issues. In one school the hostility of the anti-research camp amongst the teachers precipitated the retirement of the deputy headteacher who had led the research for ten years.

In Scotland the advent of Chartered Teachers (CT) status has generated contradictions in some schools which were feeling the need to achieve certain targets. In the context of CTs in Scotland, Reeves and Drew (2013) suggest that this created problems in the relationships between CTs and their school managers. They report that many managers found the CTs' 'activism' inappropriate which led them to try to control the incursion. Reeves and Drew (ibid.) attribute this to the friction between school improvement as a short term, closed process and action research as a more open discursive process. This is expressed by one CT as follows:

There is a difference between our understanding of collaboration and the SMT's definition of collaboration. The SMT find it quite scary that teachers will come up with the content of the project and they are nervous about the whole thing because they don't feel they have control. (Reeves \& Drew, 2013, p.41) 
Jones and Stanley (2010) provide a telling account of the tensions that can arise when different cultures or 'activity systems' interact. They argue that action research involving university researchers and 'public stakeholders' challenges the democratic traditions that underpin critical enquiry. They attribute this friction to a context of micro-politics, embedded in a culture of performativity, driven by national agendas. Thus there were disagreements over obtaining parental consent, questionnaire design, the tone of research reports and content of journal articles.

In this extended quotation from a research co-ordinator in a L2L project school there is evidence of both the contradiction and the extent to which, perhaps unusually, the dominant activity has given ground. It is well worth noting the analogy offered by the teacher - that research projects act as a 'conscience for the school'. This quotation speaks to many of the arguments made in this article - there is evidence of learning, increased agency, trust and collaboration, and changes to the school curriculum as well as the tension between the routine and reflective (Higgins, Wall, Baumfield, Hall, Leat, Moseley \& Woolner, 2007, p. 63)

Me taking on research projects in the school has made my colleagues really reflect on why they are doing what they are doing and why we're doing what we are doing as a school. I did a thing about the research, a whole staff inset evening about 3 months ago. I got some tremendous feedback from that on, that made me understand what an impact it had. In my jaundiced moments I think why am I doing this ... but actually the feedback was fantastic and a lot of people saw the research project if nothing else acting as a "conscience for the school". It is a phrase that I coined but other people bought into it, this idea that we otherwise bundle along doing stuff and not reflecting on why we are doing it.... So I think that is the least tangible thing but the thing that I notice most. That is a strange thing to say isn't it. I don't necessarily see it every day but I know that it has an effect. And, of course, the other one that has had a massive impact is the 'parents' thing. If you spoke to our colleagues five years ago about having parents in lessons - absolutely no way! Now it is just what we do, it happens every, single week and everyone is used to it.

However from the same project report (p.64) another co-ordinator reported less resilience and progress in the face of the pressure from external accountability, which threatened to reduce the lasting impact:

Well it is the initiative ...overload really and accountability. The government and their initiatives and the data driven thing and it does definitely get in the way as you 
have different pressures and it is not always what you believe in and what you feel is right ... it is all the time, you are not performing, your results are not good enough and now the self-evaluation. It (the project) is brilliant in some ways but it does add a lot of pressure because you are continually feeling that you have to be Ofsted ready all the time.

\section{Discussion}

If, as we have argued, a supportive context for teacher research is critical, we suggest that this can be leveraged at three levels. Firstly key individuals can give teachers permission to engage with research within the school, secondly support for this can be offered from beyond the school, for example by researchers or tutors from higher education institutions, and finally the policy level can create a context that values an independent and creative professionalism rather than mere subordination. In addition functional interactions between the levels can be managed to promote or demote teacher engagement in research.

The first two levels, of the school and the local context are illuminated by consideration of the work of Hubert Hermans (2001, 2013). Hermans' Dialogical Self Theory (DST) suggests that teachers, as individuals are not one person but many, and those different selves come to the fore triggered by particular contexts. All human beings, including teachers, are constantly evolving: taking on a different social complexion depending on context. Hermans suggests that individuals exist as 'voices', which represent 'internal' (I-positions) and 'external' positions (E-positions) and these voices relate to perceptions in relation to other people, phenomena or places. An I-position has a voice, which in making a case, telling a story or repeating words, has meaning for us. As the active I-position moves, prompted by changing context, we constantly re-shape our identity. DST has been important in developing theories, which recognise multiplicity, discontinuities and the embedded social nature of identity. To be engaged in dialogue does not require that we communicate with other people but that we allow existing voices emanating from I-positions to express themselves, in what Hermans has described as the democracy of the self. One might personally experience this as different voices reverberating inside the mind.

The concept of the 'dialogical self' offers an interpretation of teachers' experiences as they embark on a research study. For example, if they collaborate or cooperate at school level, they talk and listen with interest to others' parallel experiences both formally and informally. This is evident in the words of this teacher from the L2L project (Leat, 2006, p.8): 
There's a few different things really, there's the informal, we discuss an awful lot of things in the staffroom together, everyone's really open, we've got a nice community within the school, so you know as teachers we say oh we've tried this and didn't find it so good, or this really worked, or I've got this child who doesn't seem keen on this, can other people give ideas, so there's that.

This sense of the value of engaging in dialogue is found in the words of another teacher working at a local scale, involved in research practice connections in environmental education (Rickinson, Clark, Mcleod, Poulton \& Sargent, 2004, p. 207):

I appreciated the opportunity to discuss the research findings and test ideas and assumptions with practitioner colleagues

If teachers are plugged into a research support infrastructure they are also likely to hear university researchers talk, and read books and journal articles which provide them with another view and voice, which may help them develop a more dialogic and nuanced view of their school and classrooms. As a result there are more and different voices in the landscape of the mind, as Hermans might describe it. These voices are sources of interpretation and sense making of new information. They may account for what John and Prior (2003, p.236) found were the differences between two groups of teachers, those respectively with and without considerable research experience. They concluded that ( $\mathrm{p} 238$ ):

\section{The research-orientated group read the articles in a more varied and extended way ...}

This contrasted to the teachers with little research experience who had trouble in reading the articles and could not make connections with their practice. Seen through the lens of DST, there are fewer relevant voices or I-positions in the minds of the non-research orientated group through which to interpet the readings. The voices linger and interact, they return and echo, enriching internal dialogues as well as resurfacing in collegial discussions, if such discussions are given air. The critical essence of the dialogic is that it contrasts with the monologic voice of policy that insists that 'thou shalt'. Higgins et al. (2007, p.65) provide evidence of how dialogue can begin to make a serious impression on the culture of a steadfast school in the $\mathrm{L} 2 \mathrm{~L}$ project. 
We have been really encouraged with what has happened over the past three years we felt that we have been able to make judgements based on sound information. We feel the school is better informed and that we are better listeners as well both in terms of listening to staff and listening to their experiences implementing something and to listening to students about their views on how things are happening.

For schools to become ecologically supportive of teacher agency, in order to foster deep engagement in research, requires a shift away from insistent policy imperatives which demand so much of the time, energy and souls of classroom teachers. This is the third or policy level that can be conducive or hostile to teacher agency. However it is not the case that policy should simply instruct that schools conduct research and mandate what should be researched. If research engagement simply becomes another policy imperative, driven by an expectation of rapid, measurable school improvement and relentless expectation to raise standards, it is unlikely to achieve its potential. In such circumstances trust and collaboration will be in short supply and contradictions and tensions less likely to be resolved productively. Our call is for school leaders and policy makers to re-frame their perception of teachers as 'technicians' and move towards a view of teachers as 'multi-dimensional selves' who bring rich interactions of social, cultural, historical, political and personal issues to schools, classrooms and research studies. These interactions can be the building blocks of a new era of school-based curriculum development giving a new iteration to the ambitions of Lawrence Stenhouse.

A longer version of this article was developed as a background paper for the 2013 BERA/RSA Inquiry on the contribution of research in teacher education and school improvement, and can be found in the BERA website. 


\section{References}

Ball, S., (2003). The teachers' soul and the terrors of performativity. Journal of Educational Policy, 18: 215-228. DOI:10.1080/0268093022000043065

Barnett, R. \& Coate, K. (2005). Engaging the curriculum in higher education, Berkshire, UK: McGraw-Hill Education.

Biesta, G.J.J. \& Tedder, M. (2007) 'Agency and learning in the lifecourse: Towards an ecological perspective', Studies in the Education of Adults, 39(2): 132-149. (no DOI)

Bryman, A. (2008). Social research methods (3rd Edition). Oxford: Oxford University Press.

Cain, T. Holmes, M., Larrett, A. \& Mattock, J. (2007). Literature-informed, one-turn action research: three cases and a commentary, British Educational Research Journal, 33(1): 91106. DOI:10.1080/01411920601104532

Carr, W. (2007). Educational research as a practical science, International Journal of Research and Method in Education, 30(3): 271-286. DOI:10.1080/17437270701614774

Castle, K. (2006). Autonomy through pedagogical research, Teaching and Teacher Education, 22(8): 1094-1103. DOI: 10.1016/j.tate.2006.07.001

Comerford Boyes, L., Reid, I. Fox, L. \& Brain, K. (2005). Evaluation of the Creative Action Research award Scheme, Final Report for CapeUK, University of Bradford. 
Craig, C. (2004). The Dragon in School Backyards: The Influence of Mandated Testing on School Contexts and Educators' Narrative Knowing, Teachers College Record, 106 (6), $1229-1257$

Department of Education, Training and Youth Affairs (DETYA) (2000). The Impact of Educational Research. Canberra: Commonwealth of Australia. Retrieved April 14 ${ }^{\text {th }}, 2014$ from: www.detya.gov.au/highered/respubs/impact/overview.htm

Ebbutt, D., Worrall, N. \& Robson, R. (2000). Educational research partnership: differences and tensions at the interface between the professional cultures of practitioners in schools and researchers in higher education, Teacher Development: An international journal of teachers' professional development, 4(3): 319-338. DOI: 10.1080/13664530000200117

Ecclestone, K. (2000). 'Assessment and critical autonomy in post-compulsory education in the UK', Journal of Education and Work, 13(2): 141-162. DOI:

$10.1080 / 13639080050045006$

Elliott, J. (2001). 'Making evidence-based practice educational', British Educational Research Journal, 27(5): 555-574. DOI: 10.1080/01411920120095735

Elliott, J. (2012). Teaching Controversial Issues, the idea of the 'teacher as researcher' and contemporary significance for citizenship education. In: Curriculum, Pedagogy and Educational Research: The work of Lawrence Stenhouse, London \& New York: Routledge.

Emirbayer, M. \& Mische, A. (1998). 'What Is Agency?', American Journal of Sociology, 103(4): 962-1023. DOI: $10.1086 / 231294$ 
Engeström, Y. (1987). Learning by expanding: An Activity-theoretical approach to developmental research, Helsinki: Orienta-Konsultit.

Eraut, M, (2007). 'Learning from other people in the workplace', Oxford Review of Education, 33(4): 403 - 422. DOI:10.1080/03054980701425706

Eteläpelto, A. Vähäsantanen, K., Hökkä, P. \& Paloniemi, S (2013). What is agency? Conceptualizing professional agency at work, Educational Research Review, 10: 45-65. DOI:10.1016/j.edurev.2013.05.001

Freire, P. (1970). A Pedagogy of the Oppressed, New York: Seabury Press.

Furlong, J., Salisbury, J. \& Coombs, L. (2003). The Best Practice Research Scholarship Scheme: An Evaluation, A Final Report to the DfES.

Hattie, J., (2009) Visible Learning, London: Routledge

Hermans, H.J.M. (2001). 'The dialogical self: Toward a theory of personal and cultural positioning', Culture \& Psychology, 7(3): 243-281. DOI:10.1177/1354067X0173001

Hermans, H. (2013). The Dialogical Self in Education: Introduction, Journal of Constructivist Psychology, 26(2): 81-89. DOI:10.1080/10720537.2013.759018

Higgins, S., Wall, K., Baumfield, V., Hall, E., Leat, D. \& Woolner, P. (2006). Learning to Learn in Schools Phase 3 Evaluation, Year Two Report, London: Campaign for Learning. 
Higgins, S., Wall, K., Baumfield, V., Hall, E., Leat, D., Moseley, D. \& Woolner, P. (2007). Learning to Learn in Schools Phase 3 Evaluation, Final Report, London: Campaign for Learning.

Horn, I.S. \& Little, J.W., (2010). Attending to Problems of Practice: Routines and Resources for Professional Learning in Teachers' Workplace Interactions. American Educational Research Journal, 47(1): 181-217. DOI:10.3102/0002831209345158.

John, P. \& Prior, J. (2003). Conceptions, contentions and connections: how teachers read and understand different genres of educational research. This is a chapter. In Sutherland, R., Claxton, G. and Pollard, A. (Eds) Learning and Teaching: Where Worldviews Meet. Stoke on Trent, UK: Trentham Books.

Jones, M. \& Stanley, G. (2010). Collaborative action research: a democratic undertaking or a web of collusion and compliance? International Journal of Research \& Method in Education, 33(2): 151-163. DOI:10.1080/1743727X.2010.484549

Kershner, R., Pedder, D. \& Doddington, C. (2013). Professional learning during a schoolsuniversity partnership Master of Education course: teachers' perspectives of their learning experiences, Teachers and Teaching: Theory and Practice, 19, 33-49.

DOI: $10.1080 / 13540602.2013 .744197$

Leat, D. (2006). Conditions for teachers' collaborative learning: The Importance of Learning Space, Paper given at the European Conference on Educational Research, Geneva, Switzerland, September 2006. 
Leat, D., Lofthouse, R. \& Taverner, S (2006). 'The road taken: professional pathways in innovative curriculum development', Teachers and Teaching Theory \& Practice, 12(6): 657674. DOI: $10.1080 / 13540600601029686$.

Leeman, Y. \& Wardekker, W. (2014). Teacher Research and the Aims of Education, Teachers and Teaching Theory and Practice, 20(1): 45-58.

DOI: $10.1080 / 13540602.2013 .848516$

Lieberman, A. \& Grolnick, M. (1996). Networks and reform in American education, Teachers College Record, 98(1): 7-46. DOI:10.1080/02607476.2013.864018

McLaughlin, C., Black-Hawkins, K. \& McIntyre, D. (2004). Researching Teachers, Researching Schools, Researching Networks: A Summary of the Literature, Cambridge: University of Cambridge.

Marzano, R. (2003) What Works in Schools: Translating Research into Action, Alexandria, VA; ASCD.

Medwell, J. \& Wray, D. (2014). Pre-service teachers undertaking classroom research: developing reflection and enquiry skills, Journal of Education for Teaching: International research and pedagogy, 40(1): 65-77. DOI:10.1080/02607476.2013.864018

Newman, L. \& Mowbray, S. (2012). 'We were expected to be equal': teachers and academics sharing professional learning through practitioner inquiry, Teachers and Teaching: Theory and Practice, 18(4): 455-468. DOI:10.1080/13540602.2012.696046 
Nieveen, N. \& Kuiper, W. (2012). Balancing curriculum and freedom in the Netherlands, European Educational Research Journal, 11(3): 357-368. DOI: 10.2304/eerj.2012.11.3.357

Palincsar, A.S., Magnusson, S.J., Marano, N., Ford, N, and Brown, N.,(1998). Designing a community of practice: Principles and practices of the GIsML community, Teaching and Teacher Education, 14(1): 5-19. DOI: 10.1016/S0742-051X(97)00057-7

Ratcliffe, M. (2004). Science education practitioners' views of research and its influence on their practice, Evidence-based practice in science education (EPSE) research network report, Department of Educational Studies: University of York.

Rathgen, E. (2006). 'In the voice of teachers: The promise and challenge of participating in classroom-based research for teachers' professional learning', Teaching and Teacher Education, 22(5): 580-591. DOI:10.1016/j.tate.2006.01.004

Reeves, J. and Drew, V. (2013). 'A Productive Relationship? Testing the Connections between Professional Learning and Practitioner Research', Scottish Educational Review, 45(2): 36-49. (no DOI)

Rickinson, M. (2005) What do we know about practitioners' use of research? A Research Review for the National Evidence for Education Portal (NEEP) Development Group, NERF Working Paper 7.5. 
Rickinson, M., Clark, A., Mcleod, S., Poulton, P. and Sargent, J. (2004) 'What on earth has research got to do with me?' Teacher Development, 8(2): 201-220. DOI:

$10.1080 / 136645304002000020232$

Sanders, D., White, K., Sharp, C. \& Taggart, G. (2005). Evaluation of the NERF Bulletin Trial. Phase Two Report. Slough: NFER.

Sannino, A., (2008). Sustaining a non-dominant activity in school: Only a utopia?, Journal of Educational Change, 9(4): 329-338. DOI: 10.1007/s10833-008-9080-z

Stenhouse, L. (1975). An introduction to curriculum research and development, London: Heinemann.

Stenhouse, L. (1981). 'What counts as research?', British Journal of Educational Studies, 29(2): 103-114. DOI:10.1080/00071005.1981.9973589

Timperley, H., Wilson, A., Barrar, H. \& Fung, I. (2007). Teacher Professional Learning and Development: Best Evidence Synthesis Iteration. Wellington: Ministry of Education.

Wall, K., Hall, E., Baumfield, V., Higgins, S., Rafferty, V., Remedios, R., Thomas, U., Tiplady, L., Towler, C. \& Woolner, P. (2010). Learning to Learn in Schools Phase 4 and Learning to Learn in Further Education. London: Campaign for Learning. Available at: http://www.campaign-for-learning.org.uk/cfl/assets/documents/Research/Learning\%20to\%20 Learn\%20Report\%20April\%202010.pdf. 
Wenger, E. (1998). Communities of practice: learning, meaning, and identity Cambridge, UK: Cambridge University Press. 